\section{O diálogo educador entre indígenas e pedagogos(as) em formação: uma ponte para compreender e valorizar a diversidade cultural indígena brasileira Educator dialogue between indigenous and pedagogues in formation: a bridge to understand and valorize the brazilian indigenous cultural diversity}

\author{
Aumeri Carlos Bampi ${ }^{1}$ \\ Jeferson Odair Diel ${ }^{1}$
}

DOI: http://dx.doi.org/10.20435/tellus.v17i32.424

Resumo: O objeto do estudo é a força do diálogo entre estudantes de Pedagogia e indígenas, acerca da mudança de percepção sobre os indígenas brasileiros. A justificativa dá-se em virtude de que os alunos pesquisados realizam a formação em Mato Grosso, Estado brasileiro conhecido pela diversidade étnica indígena; a cidade em que estudam (Sinop) está próxima a comunidades indígenas xinguanas; no entanto esses discentes desconhecem-nas. Na pesquisa-ação envolveram-se 560 estudantes ingressantes no curso de Pedagogia entre os anos de 2008 a 2015. Aponta-se que suas percepções estavam configuradas dentro de uma visão etnocêntrica, discriminatória, descontextualizada e de subalternidade dos indígenas. O debate inicia-se com o estudo sobre a diversidade, apreciação de filmes e documentários; mas o encontro dialógico entre indígenas e estudantes atua intensamente na modificação das percepções.

Palavras-chave: diálogo; diversidade cultural indígena; formação docente; percepções.

Abstract: The study object is the dialogue force between Pedagogy students and Indigenous, about the changing of perception on the Brazilian Indigenous. The justification happens because of the surveyed students do their training in Mato Grosso, Brazilian State

\footnotetext{
${ }^{1}$ Universidade do Estado de Mato Grosso (UNEMAT), Cuiabá, Mato Grosso, Brasil.
}

Sobre os autores:

Aumeri Carlos Bampi: Doutor em Filosofia e Ciências da Educação pela Universidade de Santiago de Compostela. Pós-doutorado em Psicologia Social pela USP. Docente efetivo da Faculdade de Educação e Linguagem, do Programa de Pós-graduação em Ciências Ambientais (mestrado/doutorado) e do Mestrado em Geografia da Universidade do Estado de M ato Grosso (UNEMAT). E-mail: aumeribampi@gmail.com

Jeferson Odair Diel: Profissional Técnico da Educação Superior Efetivo da UNEMAT, Professor da UAB/UNEMATe do Programa de Pós-Graduação de Gestão Universitária da Universidade do Estado de Mato Grosso (UNEMAT). Grupo de Pesquisa Antroposfera. E-mail: jefersondiel@gmail.com 
known for Indigenous ethnic diversity; the city they study (Sinop) is near the Xingu Indigenous communities; however, these students ignore them. In the action research, it was involved 560 pedagogy freshmen between the years of 2008 and 2015. It is pointed that its perceptions were configured inside an ethnocentric, discriminatory, decontextualized and subalternity vision of the Indigenous. The debate starts with the study about the diversity and appreciation of movies and documentaries; but the dialogic meeting between Indigenous and students act strongly in the changing of perceptions.

Key words: dialogue; indigenous cultural diversity; teacher training; perceptions.

\section{INTRODUÇÃO}

O estudo sobre o diálogo educador entre indígenas e estudantes de um curso de Pedagogia, formação de professores: uma ponte para compreender e valorizar a diversidade cultural indígena traz à tona a realidade de como desenvolver atividades formativas da disciplina de Antropologia, presente no curso de Pedagogia, para tratar da questão da formação do povo brasileiro. $\mathrm{O}$ Curso de Pedagogia no Brasil se dedica a capacitar profissionais da educação infantil e ciclo básico - alfabetização e números.

Com o desenrolar das atividades, o que se notava é que havia por parte dos estudantes uma espécie de negação ou ocultamento dessa constituição étnica e sociocultural diversa. Foi justamente refletindo sobre essa questão e, consequentemente, buscando encontrar uma forma de amenizar esse distanciamento, que se originou este trabalho que versa sobre como se sucedeu a interação dos estudantes de Pedagogia em seu processo formativo com a existência dos povos indígenas no Brasil atual.

Como proposta, ao invés de somente fazer um desenvolvimento de abordagem teórica e sem contextualização nas aulas de Antropologia do curso de Pedagogia, os estudantes, instigados pelo professor da disciplina, organizaram pesquisas e estudos participativos e interativos. A esses eventos, os indígenas se deslocavam até a Universidade para participarem das atividades, tais como seminários, exposições, debates e apresentações.

Os resultados desse trabalho alcançaram intensa significação junto aos estudantes. Manifestaram ainda a importância do processo interativo, que aconteceu como método de busca de superação da realidade de desconhecimento, negação e desvalorização dos povos indígenas, percepções presentes na comunidade universitária pesquisada.

Este estudo está dividido em quatro partes, sendo a primeira a que versa sobre como a invisibilidade acerca dos indígenas adentra a universidade na percepção dos estudantes; a segunda trata dos caminhos teórico-metodoló- 
O diálogo educador entre indígenas e pedagogos(as) em formação: uma ponte para compreender e valorizar a diversidade cultural indígena brasileira

gicos da pesquisa; a terceira procura analisar a força do diálogo na educação para a diversidade no curso de formação de pedagogos(as). Por fim são feitas as considerações do trabalho.

\section{A "INVISIBILIDADE INDÍGENA" ADENTRA A UNIVERSIDADE}

O Brasil é um país formado por uma ampla e diversa base étnica e cultural. Como diz Ribeiro (1995), as matrizes constituintes do Brasil são a tupi, a lusitana e a afro. Obviamente que devem ser considerados os diversos povos europeus e povos asiáticos que adentraram ao Brasil quando da colonização e imigração; no entanto, se essa formação sociocultural é sabida e reconhecidamente explícita de maneira histórica, linguística, sociológica e antropológica, ou seja, do ponto de vista científico, o mesmo não vale dizer para as percepções sociais, políticas e representações que possui seu próprio povo de si mesmo (RIBEIRO, 1995; SEKI, 1999; RODRIGUES, 2006; LUCIANO, 2006).

Nega-se ou não se dá como perceptível a diversidade étnica e cultural junto aos estudantes. Essa negação, no entanto, acontece essencialmente em relação à participação da figura do indígena quer na participação da história do país, quer de sua existência e principalmente na composição da sociedade brasileira contemporânea.

Tal situação manifestava-se após os questionamentos realizados pelo professor-pesquisador junto aos estudantes da disciplina de Antropologia. As indagações feitas aos estudantes eram as seguintes: - Quem são os indígenas brasileiros? - Como eles aparecem na atualidade? - Como os indígenas participam da sociedade nacional contemporânea? - Quantos povos indígenas conhecem? - Quantas línguas indígenas são faladas no país? Onde estão os indígenas?

Tais questionamentos eram realizados dentro da abordagem dada pela disciplina, em diversos momentos pedagógicos, referindo aquilo que Ribeiro (1995) chama de matriz indígena como componente da sociedade nacional brasileira. Para isso, o método antropológico ver, ouvir e registrar (OLIVEIRA, 2000) foi utilizado em atenção ao que falavam os estudantes. A observação bem como a escuta das falas e o devido registro foram executados pelo professor-pesquisador.

O que se descobriu é que havia uma espécie de rechaço da existência do indígena por parte dos estudantes e um estranhamento, além de manifestações etnocêntricas e discriminatórias que eram expostas sobre o "índio". Tal situação repetia-se semestre a semestre a cada período inicial do curso. 
A situação é reveladora do contexto da fronteira de expansão geográfica do capitalismo rumo à Amazônia, onde se constroem cidades, amplia-se a fronteira agrícola, fundamentalmente por migrantes sulistas, ignorando a sociodiversidade amazônica e os povos autóctones, em uma espécie de replicação do que se sucedeu ao longo da história brasileira (SILVA, 2007).

Quatro percepções principais foram detectadas a partir das falas dos estudantes, que podem ser assim sintetizadas:

1 - Desconhecimento em relação à diversidade de povos indígenas do país, do Estado de Mato Grosso e do entorno (Parque Indígena do Xingu):

Não sei quantos índios vivem no Mato Grosso. No Brasil se vê pouco. Acho que na Amazônia talvez ainda existam algumas "tribos". De vez em quando aparece na televisão (ALUNO DE GRADUAÇÃO, 2008).

No Rio Grande do Sul sei que existiam bugres. Mas não são índios, não! (ALUNA DE GRADUAÇĀO, 2009).

Penso que todos falam a mesma língua, pois são índios. Índio é 'tudo' a mesma coisa (ALUNA DE GRADUAÇĀO, 2010).

Os índios são todos iguais, falam a mesma língua! A maioria fala português. Eles vêm sempre na loja onde trabalho (ALUNA DE GRADUAÇÂ, 2011).

Eu não sei de índios não! Penso que existiram no passado, mas hoje todos falam o português e se vestem como nós, andam de camionetes, carros, com celular, usam tênis, roupas, como nós! Não são mais índios não! Não existe mais gente que vive no mato (ALUNA DE GRADUAÇÃO, 2012).

A gente sabe dos índios quando bloqueiam estradas! Nem sei de onde saem (ALUNA DE GRADUAÇÃO, 2013).

Às vezes eu vejo alguns que parecem índios, acho que é família, no hospital ou posto de saúde. Parecem que são paraguaios, bolivianos, sei lá (ALUNA DE GRADUAÇÃO, 2015).

Ah, mas sei que existem índios sim. São violentos! Um primo meu sofreu violência deles quando bloquearam a rodovia! Nem me fale em índios! Tive uma experiência ruim porque foram violentos com um familiar meu no Mato Grosso do Sul num bloqueio (ALUNA DE GRADUAÇÃO, 2015).

2 - A presença de um forte etnocentrismo nos estudantes, que está ligado ao modo de relações sociais presentes nas cidades de expansão da fronteira agrícola em direção à Amazônia. Repetem o modelo de desenvolvimento do Sul-Sudeste do país calcado em uma visão colonialista e de subalternidade dos indígenas:

É uma imensidão de terra a uns poucos vagabundos! E ainda cobram pedágio para passar nas terras deles! Depois querem vir na cidade e ganhar as coisas (ALUNA DE GRADUAÇÃO, 2008). 
O diálogo educador entre indígenas e pedagogos(as) em formação: uma ponte para compreender e valorizar a diversidade cultural indígena brasileira

Aqui em Mato Grosso, os índios queimaram e destruíram o canteiro de obras de uma usina, invadiram prefeituras, são violentos, tem que ser civilizados (ALUNA DE GRADUAÇÃO, 2009).

Professor, os índios são acomodados! Eles não querem nada! Somente querem dinheiro do governo! E há até ONGs e igrejas que ajudam (ALUNA DE GRADUAÇÂO, 2010).

$\mathrm{Na}$ verdade, os índios gostam é de ter muita terra e dinheiro. Gostam muito de cachaça (ALUNO DE GRADUAÇÃO, 2013).

Não tem futuro a vida deles, dos índios! Irão acabar morando nas cidades (ALUNO DE GRADUAÇÃO, 2014).

Os índios são todos iguais. Eles não querem trabalhar, são preguiçosos. Ficam esperando o governo dar as coisas. Querem barcos, camionetes e avião. Tomara que aconteça a CPI da FUNAI (ALUNA DE GRADUAÇÃO, 2015).

3 - Descontextualização e destituição do "ser" indígena como participante da sociedade nacional. Índio não existe mais. Os que existem são seres que querem se passar por índios para obter privilégios;

Índio, de verdade, nem existe mais! Há gente que quer se passar por índio. Eu acho que é para conseguir vantagens, ou por influência de ONGs internacionais (ALUNA DE GRADUAÇÃO, 2009).

Dizer que existe índio é coisa da FUNAI e ONGs. Inventam índios, sei lá com que interesses (ALUNA DE GRADUAÇÃO, 2011).

A sociedade brasileira é feita dos brancos europeus e também dos negros. Índios mesmo, eu acho que são raros os descendentes (ALUNA DE GRADUAÇÃO, 2012).

Tem o fazendeiro, construiu sua fazenda, trabalhou, batalhou, e de repente aparece alguém dizendo que é terra indígena. É uma loucura. Tem até cidades feitas e aí a justiça e FUNAI querem expulsar todo mundo (ALUNA DE GRADUAÇÃO, 2013).

Dá revolta na gente ver que querem tirar as pessoas que construíram a cidade, as fazendas, até os pequenos sitiantes. Não tinha nada lá e agora aparecem índios não sei de onde como no Araguaia (ALUNA DE GRADUAÇÃO, 2014).

4 - A figura do "índio" é a de um ser improdutivo e entrave ao desenvolvimento. Causa problemas, atrapalha o desenvolvimento econômico e social do país e nada produz. Vive no atraso.

Chamamos alguém de índio quando vive no atraso. Dizemos: parece até índio! Parece bicho do mato, porque não conhece as coisas (ALUNA DE GRADUAÇÃO, 2008).

Para que tanta terra aos índios! Não fazem nada! É desperdício! Imagine o que se poderia produzir em tanta terra. E depois ainda há gente que fala em fome (ALUNA DE GRADUAÇÃO, 2010). 
É só aparecer uma obra importante ao país, uma rodovia, uma usina, um local com ouro, diamante, que surgem 'índios'! Nem se sabe de onde aparecem. Só atrapalham! Acho que é uma forma de travar o desenvolvimento. É difícil lidar com eles (ALUNA DE GRADUAÇÃO, 2012).

No Mato Grosso, os índios travam o desenvolvimento. E, mesmo assim, são privilegiados porque possuem muita terra. Milhares de hectares para quê? (ALUNA DE GRADUAÇÃO, 2013).

Se eles (índios) têm tanta terra, por que não trabalham? Por que não produzem? Por que não vendem madeira, criam gado? Pisam em riqueza, mas são miseráveis (ALUNO DE GRADUAÇÂ, 2015).

O problema de pesquisa-ação se constituiu, abrindo caminhos a uma necessária formação desses estudantes. Colocaram-se então diante dos estudos de Antropologia, no curso de Pedagogia, questionamentos que poderiam constituir possíveis caminhos às respostas formativas necessárias.

Por que, afinal, os estudantes da licenciatura em Pedagogia negam ou omitem a participação indígena na formação do povo brasileiro? Como percebem o indígena? Como fazer para que, a partir dos estudos de Antropologia (disciplina desenvolvida no período de formação inicial do curso), possam, enquanto professores em formação, compreender e acercarem-se da realidade da diversidade cultural e linguística brasileira? Como poderiam tratar de maneira adequada a diversidade cultural indígena do país nas salas de aula nos processos ensino-aprendizagem quando estiverem atuando como profissionais da educação?

A abordagem aos estudantes da Pedagogia foi feita levando em consideração que seus estudos estavam sendo desenvolvidos dentro de um contexto de ampla riqueza e diversidade linguística e cultural indígena que é o Estado de Mato Grosso, o qual possui mais de quatro dezenas de etnias e ampla diversidade linguística. Levou-se em conta, ainda, que os estudantes realizavam estudos na cidade de Sinop, pertencente à Amazônia meridional que dista aproximadamente 150 a 200 km do Parque Indígena do Xingu, constituído por 16 povos indígenas diferentes; no entanto, esses discentes desconhecem-nos e sequer sabem de sua existência.

Mas o fator preponderante, levado em consideração, era o de que esses estudantes seriam futuros professores da educação básica, agentes multiplicadores no processo educativo, sendo, portanto, imprescindível que suas percepções fossem aproximadas à realidade da diversidade cultural existente no Brasil e a necessidade de seu conhecimento, valorização e preservação.

A educação, assim posta, poderia ser o eixo da preservação da diversidade cultural e da criação de um espaço democrático, que torne possível o encontro e o diálogo de culturas. Atualmente, esta reflexão é funda- 
O diálogo educador entre indígenas e pedagogos(as) em formação: uma ponte para compreender e valorizar a diversidade cultural indígena brasileira

mental para imaginar como viver a multiculturalidade que caracteriza as sociedades contemporâneas. A perspectiva intercultural, aplicada na educação e em outros domínios das ciências humanas, refere-se à interação, à reciprocidade, à interdependência e ao intercâmbio que regem as relações entre culturas, na compreensão do mundo. A educação, partindo dessa perspectiva, como transmissora de valores fundamentais, constitui a essência para imaginar projetos de sociedades viáveis, capazes de garantir a dignidade de que todos precisamos. (MARÍN, 2006, p. 37).

\section{CAMINHOS TEÓRICO-METODOLÓGICOS}

A investigação aqui relatada foi realizada junto ao curso de Pedagogia, da Universidade do Estado de Mato Grosso, na cidade de Sinop, abarcando os ingressantes à primeira fase do curso desde o segundo semestre do ano de 2008, até o primeiro semestre do ano de 2015. O curso possui ingresso semestral. Totalizam 560 os universitários pesquisados pertencentes ao processo formativo de licenciatura.

A pesquisa, desenvolvida durante oito anos, apontava a cada ingresso para um problema essencial: a questão da invisibilidade da matriz indígena em sua diversidade à formação do povo brasileiro, exposta pelos estudantes.

Diante dessa questão, um dos trabalhos iniciais era a apresentação das matrizes que constituíram a "brasilidade", expostas a partir do estudo da obra de Darcy Ribeiro, A formação do povo brasileiro - as diversas matrizes constituintes da sociedade brasileira.

Posteriormente, foram realizadas pesquisas, leituras, apreciação de filmes e documentários e debates que forneciam subsídios ao entendimento da realidade da diversidade cultural indígena na formação da sociedade brasileira. Os estudos realizados não conseguiram dar conta de uma aproximação real com o contexto estudado e com a tentativa de compreensão dos aspectos elencados nas percepções dos estudantes.

O estudo das etnias diversas, conhecimento do nome das etnias, povos e línguas, sua localização, seus modos de vida e relação sociedade/natureza de certa forma apareciam como superficiais e distantes de entendimento. Surgiu então uma proposição, para que a realidade de invisibilidade pudesse ser superada.

O professor-pesquisador propôs um método, como fórmula reversa do trabalho de campo proposto nas pesquisas antropológicas. Ao invés de ir a campo, dada a impossibilidade de visita pelos estudantes às aldeias e comunidades indígenas, o campo seria procurado, contatado e trazido às atividades formativas. Não se trata apenas de um campo físico ou geográfico, 
senão que o de um campo vivo, constituído de pessoas, línguas e culturas que poderiam trazer à universidade o olhar diverso e necessário que deveria ser desenvolvido nas atividades da disciplina de Antropologia como contribuinte aos(às) pedagogos(as) em formação.

Foram então propostos seminários de pesquisa-ação. A finalidade seria a de discutir questões referentes à formação do povo brasileiro, diversidade étnica, diversidade cultural, diversidade linguística e a situação sócio-econômica-cultural das populações, daquilo que se convenciona chamar de sociedade brasileira em suas diferentes matrizes e línguas.

No tocante às populações indígenas, os seminários propostos deveriam buscar a presença de representantes ou de membros de comunidades indígenas diversas, para que falassem sobre suas culturas, línguas e forma de viver. A partir da organização dos seminários, foram então realizados convites de modo que viessem participar junto à universidade e à formação de professores, contribuindo aos estudos a partir do diálogo com os estudantes. O convite foi muito bem acolhido pelos indígenas e aceito durante todos os anos.

Nesse caso, a possibilidade da participação contava com dois fatores facilitadores: primeiro havia a presença de membros de comunidades indígenas que participam da educação superior na cidade de Sinop/MT, e o segundo foi a presença da Casa de Apoio a Saúde Indígena (CASAI) (unidade ligada à Secretaria Especial de Saúde Indígena - Ministério da Saúde) na cidade de Sinop/MT. Essa unidade serve de apoio ao tratamento de saúde dos povos do baixo e médio Xingu, estabelecidos no Parque Indígena do Xingu, onde há presença constante de membros de diversos povos que se deslocam para realizar tratamento de saúde ou acompanhamento de familiares que dele necessitem.

Metodologicamente, o estudo, em sua fase inicial, propunha sempre a busca de um conhecimento prévio sobre as comunidades indígenas do país, do Estado do Mato Grosso e das comunidades do entorno, em especial as pertencentes ao Parque Indígena do Xingu, pois seriam as contatadas. Em um segundo momento, propunha a interação cultural.

Assim, a metodologia dos seminários seguiu a pesquisa de levantamento, o estudo interpretativo e a apresentação, trazendo como acréscimo a realização da interação cultural como forma de evidenciação da realidade de diversidade cultural presente no contexto da Amazônia norte-mato-grossense e do Parque Indígena do Xingu. O contato direto tinha a intenção interativa e dialógica, de modo que os indígenas expusessem suas culturas, línguas e modos de existência. A partir do encontro, abriu-se um diferente espaço formativo na universidade. 
O diálogo educador entre indígenas e pedagogos(as) em formação: uma ponte para compreender e valorizar a diversidade cultural indígena brasileira

Nesse sentido, os seminários alcançaram alta produtividade e profundo significado junto aos estudantes, demonstrando a importância de o processo interativo acontecer como método de busca de desconstrução de estereótipos e preconceitos presentes na comunidade universitária pesquisada e maior valorização dos povos indígenas.

No entanto observa-se que, antes do desenvolvimento dos seminários, eram realizadas atividades de memória cultural com os alunos em dias antecedentes aos seminários. Tais momentos tornavam explícitos elementos importantíssimos ao entendimento da realidade indígena brasileira.

A realização do exercício da memória cultural com os estudantes foi um especial momento de descobertas tanto individuais quanto coletivas e serviu para a socialização e entrosamento, além de analisar e questionar situações colocadas pelos próprios estudantes de modo etnocêntrico, preconceituoso e descontextualizado no tocante ao ser indígena. No processo de socialização de tal memória, os estudantes percebiam que muitos deles próprios, como outros tantos brasileiros, são indígenas. Houve uma média de $1 / 3$ a até metade dos estudantes em cada turma pesquisada que manifestaram ser descendentes de indígenas por autodeclaração. Foi citado o pertencimento às seguintes etnias: Guarani, Kaingang, Guarani Kaiowá, Guajajara, Bororo, Umutina e Chiquitano.

Pertencer a alguma etnia ou descender de comunidades indígenas era questão exposta somente a partir do momento em que os estudantes haviam realizado o estudo e entendida, ainda que parcialmente, a situação dos indígenas na realidade brasileira. Havia medo do preconceito e discriminação dentro do curso e da universidade, por isso a manifestação de pertencimento à descendência de alguma comunidade indígena ocorreu somente após a análise dos equívocos ou estereótipos presentes nos grupos de estudantes.

Nesse sentido, a manifestação de pertencimento por parte dos alunos a alguma descendência étnica indígena era importante lição pedagógica, uma vez que se manifestaram identidades culturais sufocadas. Diversos alunos manifestaram que, desde crianças, no contexto escolar ou social, tinham de esconder sua identidade cultural indígena, em virtude do menosprezo social construído e fortemente presente na realidade brasileira em relação aos indígenas. Diziam ainda os estudantes que as escolas e os livros didáticos, bem como muitos professores e gestores da educação contribuíram para a construção e difusão do preconceito.

Outros estudantes redescobriram suas identidades indígenas após conversar com a mãe, pai, avô ou avó, revendo a história de seus ancestrais. Nesse sentido, a explicitação da memória cultural também pode ser vista como libertadora, pois proporciona o entendimento de quem somos e que cultura nos constituiu. 


\section{O DIÁLOGO EDUCADOR ENTRE INDÍGENAS E PEDAGOGOS(AS): A PRESENÇA, O FACE A FACE E A INTERAÇÃO}

A realização dos seminários, a cada semestre, durante oito anos, ocorreu com a presença de membros de comunidades indígenas, durante os diversos anos, perfazendo um total de 138 participantes de etnias diversas, dentre as quais cabe citar: Guajajara, Juruna, Ikpeng, Kaiabi, Kaiapó, Panará, Terena, Trumai, Umutina e Waurá. Estiveram presentes homens e mulheres, crianças, jovens, adultos e idosos indígenas. Participaram ainda professores indígenas, alunos do terceiro grau indígena da Universidade do Estado de Mato Grosso, agentes de saúde indígena xinguanos, estudantes indígenas junto à Universidade Federal de Mato Grosso, caciques e pajés.

Observa-se que a comunidade Guajajara não é pertencente ao Estado de Mato Grosso, mas ao Estado do Maranhão; no entanto um membro da comunidade Guajajara, mulher, casada com não indígena havia migrado ao Estado de Mato Grosso, à cidade de Sinop. Destaca-se que a participação dessa etnia está relacionada à de uma estudante, pertencente ao curso de Pedagogia. Ao buscar informações sobre sua mãe, evidenciou seu pertencimento étnico. Essa indígena, mãe da estudante, convidada a fazer uma exposição de seu modo cultural, sua etnia e língua, relatou que sempre teve de ocultar essa informação, quer de seus filhos ou mesmo no contexto social, quando da busca por trabalho, ou mesmo na convivência cotidiana. Relatou ainda que manteve silêncio quanto a seu pertencimento étnico em virtude da discriminação sofrida, pois possuía medo de que ela e mesmo os filhos tivessem problemas e represálias ao se manifestarem como indígenas. Recentemente, constituiu um processo judicial para inserção do nome étnico em seu sobrenome.

A presença de membros de comunidades indígenas junto aos estudos de formação de professores, a partir da disciplina de Antropologia, foi reveladora da força da presença (contato, interação), do face a face (olhar) e do diálogo (conversar, escutar).

\subsection{A importância do indígena na universidade: ver e sentir a presença do outro}

A presença indígena nos seminários trouxe o contato pessoal. Os indígenas estiveram presentes como humanos que são, como pertencentes a um povo, a uma comunidade e sociedade, portadores de uma cultura. Iguais aos estudantes enquanto humanos, mas, ao mesmo tempo, diferentes enquanto seres socioculturais. A visibilidade dessa existência igualdade/diferença, singularidade/pluralidade foi uma manifestação importante para problematizar 
O diálogo educador entre indígenas e pedagogos(as) em formação: uma ponte para compreender e valorizar a diversidade cultural indígena brasileira

a percepção, como diz Freire (2002), de que o índio era um ser genérico do passado colonial. Outra questão referente ao contato, à presença foi mostrar o "índio" vivo, na atualidade, constituinte de famílias, de comunidades, de aldeias, de povos e constituinte vivo da nação brasileira.

Quem poderia imaginar que os 'índios' são como nós, que existem ainda hoje com línguas tão diferentes, com vida tão diferente da nossa. Que riqueza imensa temos e não nos damos conta (ALUNA DE GRADUAÇÂO, 2008).

Eu pensava que no Brasil só se falava português. Mas hoje percebi que existem outras culturas e línguas vivas com os indígenas (ALUNA DE GRADUAÇÃO, 2009).

Sabe, vê-los assim, poder conversar, faz diferença. Aprendemos de modo errado sobre os indígenas, quem e como eles são. Eu aprendi que não existiam mais. Dá até vergonha do que eu pensava (ALUNA DE GRADUAÇÃO, 2009).

Foi muito importante tê-los em sala de aula, pessoalmente. Mudou o que pensava sobre eles, que era baseado em muito preconceito que aprendi do lugar de onde venho. Ver aquela família Kaiabi, pai, mãe, crianças falando conosco foi interessantíssimo. Foi um encontro muito humano, muito bonito (ALUNA DE GRADUAÇÃO, 2011).

Eu fiquei impressionada com a fala daquela senhora idosa do povo Trumai e seu neto traduzindo o que dizia. Foi marcante ver que ela não tem raiva de nós, que ela diz que cada um pode ter seu modo de vida, respeitando o outro (ALUNA DE GRADUAÇÃO, 2009).

Eu tive a oportunidade de conhecer e conversar com o cacique Melobô Ikpeng. Dizem que é uma das grandes lideranças do Xingu. Ele falou muito sobre a história do Xingu, de como seu povo sofreu com doença, matança, perseguição, mas que resistiram (ALUNO DE GRADUAÇÃO, 2010).

Conversando com a Yré Kaiabi, descobri que ela faz o curso de Administração na própria UNEMAT. O Alvanei Reginaldo, do povo Terena, estuda Enfermagem na UFMT. O professor Kaiabi fez faculdade em Barra do Bugres. Eu não tinha ideia de que eles tinham interesse por estudar, que fazem faculdade, igual a nós (ALUNA DE GRADUAÇÃO, 2012).

A participação dos indígenas ocorreu de forma voluntária, atendendo ao convite dos estudantes universitários. A presença, a fala dos indígenas junto aos estudantes demonstrava que as sociedades indígenas são realidade do tempo presente na sociedade brasileira. Outra questão importante foi que os diversos grupos e etnias demonstraram como organizam a sobrevivência e existência, dentro de um modo altamente complexo de relação sociedade/ natureza junto à floresta (BAMPI; DIEL, 2015).

Então a visibilidade buscada não foi constituída apenas pela aparência, de modo que os estudantes "apreciassem-nos" como se esses indígenas 
estivessem em um zoológico para serem observados como pertencentes ao exótico. Pelo contrário, as presenças de famílias indígenas, adultos, velhos, crianças, casais demonstraram à comunidade universitária pesquisada que são humanos em todas as suas dimensões. Igualmente, suas culturas merecem respeito e atenção, em especial frente aos processos de pressão e homogeneização cultural que sofreram no processo de colonização e mesmo nos dias atuais com o alargamento do espaço geográfico capitalista via agronegócio, usinas hidrelétricas ou cidades na Amazônia.

Nos dias que correm, no contexto brasileiro, ainda sofrem o confinamento pressionado em reservas e parques, sempre atentados pela vontade e ganância capitalista de exploração e tomada de seus territórios pelo agronegócio, atividades mineradoras ou construções de usinas hidrelétricas, ou da imposição da fé por doutrinação religiosa.

O contato presencial dos indígenas com os universitários, do curso de Pedagogia, obviamente, incluiu a dimensão afetiva, estabelecendo laços, apertos de mão, abraços, olhares, escutas de línguas diferentes, observação estética, pegar no colo uma criança indígena, aprender a tecer com fios de algodão com uma mulher indígena, conversar sobre a estética indígena feminina, falar sobre relacionamentos, comer juntos, tirar fotografias, pedir às crianças indígenas para mostrarem como brincar e se divertir, uma vez que tal contato não se baseou apenas em uma participação intelectualista. O essencial da presencialidade era sentir o outro em sua integralidade.

Foi um momento especial em minha vida ter tido esta experiência de saber da existência dessas culturas tão ricas e diferentes. Mas poder segurar no colo a criança, conversar com ela, com sua mãe, saber como cuida, como ensina e como a alimenta foi maravilhoso. Ela ainda nos contou como ocorrem os relacionamentos e casamentos, a educação, a alimentação na aldeia e como fazem os tecidos, pinturas e os cestos (ALUNA DE GRADUAÇÃO, 2013).

\subsection{A importância do diálogo com os indígenas: escutar e falar com o outro}

O escutar e questionar, o "ver, ouvir e registrar" estiveram presentes no desenvolvimento dos seminários. Ao abrir espaço para que os membros de diversas comunidades indígenas expusessem seus modos de vida, suas culturas, suas línguas, trabalho, existência e sobrevivência, os estudantes em formação colocavam-se pedagogicamente abertos à escuta do outro. Essa escuta servia como elemento de abertura ao entendimento do ser historicamente negado no contexto brasileiro: o indígena, ou os indígenas ocultos em sua diversidade cultural. 
O diálogo educador entre indígenas e pedagogos(as) em formação: uma ponte para compreender e valorizar a diversidade cultural indígena brasileira

Foi maravilhoso tê-los conosco. Eu não imaginava a riqueza e sabedoria que eles têm. Foi muito bom escutá-los. Aprendi muito (ALUNA DE GRADUAÇÃ̃, 2009).

Eu nunca havia visto um índio, muito menos tinha escutado o que pensam sobre eles e sobre nós, nossa sociedade. Acho que temos que repensar o que ensinamos nas escolas sobre eles (ALUNA DE GRADUAÇÂO, 2010).

Estou admirada com a sabedoria do cacique Kaiabi, de como funciona a sua cultura, que ainda falam sua língua, como se organizam, qual é o papel que ele tem na aldeia, como eles trabalham, fazem suas roças, suas casas, alimentos, como são os relacionamentos e casamentos (ALUNA DE GRADUAÇÃO, 2012).

Ter uma conversa é muito diferente de ouvir o que dizem por aí ou mesmo na televisão, que os "índios" são ignorantes, não trabalham, não fazem nada. Agora sei que isto é mentira! Eles nos explicaram como é a vida deles nas aldeias (ALUNA DE GRADUAÇÃO, 2013).

As falas dos membros de comunidades indígenas eram acompanhadas de muita atenção e observação por parte dos alunos, sendo algumas apresentações e falas em sua própria língua, com tradução de algum outro membro, ou mesmo em português.

Vocês, na universidade, na escola podem mostrar quem é o índio, o que o índio quer, que nós não queremos nada dos outros, mas garantia da nossa vida, nossa terra. Nós também trabalhamos para sustentar filhos. Precisamos que nossa terra se conserve (CACIQUE DA ETNIA KAIABI, 2009).

A nossa escola não pode ser feita só por vocês não índios. Nossa comunidade quer participar da escola, da educação, aquilo que (se) ensina na escola. Tem que ouvir anciãos, ouvir a comunidade. Assim se faz verdadeira educação (PROFESSOR, MEMBRO DA ETNIA KAIABI, 2010).

Os Terenas, depois de uma longa caminhada, vieram ao Mato Grosso. Mas moravam no Mato Grosso do Sul. Com a pressão dos fazendeiros ficaram sem terra para viver. Viveram um tempo em Rondonópolis, mas queriam um lugar próprio, por isso vieram ao norte de Mato Grosso, terra onde nosso avô já tinha passado (ALVANEI REGINALDO, ETNIA TERENA, 2011).

Causava espanto e admiração o fenômeno do bilinguismo indígena, o multilinguismo, especialmente porque, no Parque Indígena do Xingu, membros de diversas comunidades dominam diversas línguas étnicas, além do português.

Eu nem sabia que eles falavam línguas próprias e também falam a língua dos povos vizinhos, além do português. Nem sabia que existiam dezesseis povos diferentes no (Parque Indígena do) Xingu (ALUNA DE GRADUAÇÃO, 2008). 
Eu nunca imaginei um indígena falando duas ou três línguas. Achei surpreendente. Como falar que são ignorantes? (ALUNA DE GRADUAÇ $\tilde{A} O$ 2009).

Quando o professor indígena (Kaiabi) falou de sua trajetória escolar e disse que havia reprovado cinco vezes na primeira série, eu fiquei sentida. Disse que quando ele foi para a escola não sabia português e só lhe ensinavam em português. Mas depois fiquei feliz por saber que quando seu filho foi à escola não reprovou nenhuma vez, porque ele, pai, havia se tornado um professor e ensinava na língua (Kaiabi) e também em português (ALUNA DE GRADUAÇÃO, 2010).

Eu nunca havia visto um livro escrito em língua indígena como aquele que o professor Ikpeng nos mostrou. São histórias e mitos do seu povo e foi escrito por eles (ALUNA DE GRADUAÇÃO, 2012).

Outros ficaram encantados com a demonstração de métodos e processos de sobrevivência, construção de casas, barcos, processos de pesca, caça e coleta, de organização do trabalho, da cura de doenças, cosmologia, mitos, rituais e festividades.

Cada povo tem um jeito de caçar, de pescar, de construir suas casas, de fazer roças. Eu pensava que todos os indígenas construíam suas casas do mesmo jeito. Mas eles possuem arquitetura e métodos de construção diferentes. As pinturas corporais, os desenhos, os objetos também são diferentes. Há diferença na cultura entre um povo e outro (ALUNA DE GRADUAÇÃO, 2009).

A gente pensava que eles não trabalhavam. Agora vemos que trabalham como nós, mas em atividades diferentes das nossas. Eles têm habilidades, jeitos diferentes para fazer as coisas, mas têm que ter muito conhecimento e sabedoria para viver na floresta (ALUNA DE GRADUAÇÃO, 2011).

Por vezes, a presença de etnias diversas em um mesmo momento auxiliava o entendimento sobre as diferenças culturais dos indígenas, levando-os a perceber o sentido da diversidade cultural indígena no país. Assim era percebido que o "índio" genérico não existe, senão um conjunto diverso de povos indígenas com práticas socioambientais distintas.

Quando vi seis línguas (indígenas) diferentes sendo faladas na aula (seminário) é que comecei a entender o que é a diversidade cultural, que isto existe. Antes era algo sem muito sentido para mim, só discurso! Achava os índios todos iguais, mas percebi que não são (ALUNA DE GRADUAÇÃO, 2010).

Nós aprendemos na escola a ver as coisas de um modo mascarado. Hoje vejo que na escola que fiz não fui ensinada a compreender a diversidade. Ainda bem que na universidade aprendi diferente, senão iria ensinar do mesmo jeito aos meus alunos (ALUNA DE GRADUAÇÃO, 2014).

O falar, o expor, conversar dava-se como um elemento imprescindível à problematização da visão discriminatória, estereotipada e etnocêntrica que 
O diálogo educador entre indígenas e pedagogos(as) em formação: uma ponte para compreender e valorizar a diversidade cultural indígena brasileira

os estudantes eram portadores, em virtude do contexto social que participam. Mas não apenas compreensão daquele indivíduo falante, senão como funcionavam as culturas em sua diversidade, como eram organizadas as suas sociedades, o que faziam para sobreviver, como reportavam saberes e fazeres, como se dava a educação e socialização das crianças, como era a organização social dos adultos nas aldeias e comunidades.

Após a fala dos membros das comunidades indígenas, em cada seminário, estava aberto o diálogo. As descobertas foram acontecendo naturalmente, uma vez que, como em uma espécie de ecologia de saberes, culturas distintas se encontraram. O diálogo servia como ponte educadora, como caminho para analisar e discutir um conjunto de equívocos colocados sobre os indígenas brasileiros como seres do passado, como seres de culturas que devem permanecer congeladas, como seres que não possuem trabalho, que são improdutivos. Além desses aspectos, a relação sociedade/natureza era mostrada pelos indígenas, questionando o modo de desenvolvimento não indígena, uma vez que manifestavam sobre como a degradação ecológica da Amazônia, a homogeneização cultural e o modelo de produção e consumo da sociedade capitalista afeta-os diretamente.

É muito importante Melobô falar aqui, porque agora vocês conhecem que tem povos diferentes no Xingu, que precisam respeitar meu povo, natureza e nossos parentes. Por isso nós também quer(emos) escola. Filho meu também é professor e ensina na comunidade. Ikpeng também precisa de escola. Nós (tivemos que) enfrentar violência, armas, doenças dos brancos. Foi tempo difícil para (a) comunidade Ikpeng e nossos parentes (CACIQUE MELOBÔ IKPENG, 2009).

Vocês têm modo diferente do nosso, mas podemos conviver. (Mas) não é certo destruir a vida, nossa terra, a floresta, os rios estão acabando. Não podemos viver sem eles. Sinop era terra Kaiabi, era tudo floresta, Teles Pires era bonito rio. Hoje (está) muito destruído. Família Kaiabi vivia por aqui. Povo Kaiabi teve que ir embora ao Xingu. Hoje (a) cidade, terra daqui é só de vocês (CACIQUE DA ETNIA KAIABI, 2011).

Não índio fala muito, mas faz contrário. Diz que ensina ambiente, mas suja e destrói tudo, floresta, rio, faz queimada. Branco precisa respeitar o índio. Branco pensava que índio era bicho, não gente. Índio é gente igual vocês (ANCIÃ TRUMAI, 2010).

Antigamente era muita floresta. Hoje está acabando. Madeireiro quer madeira, mas não planta. Só quer derrubar. Fazendeiro quer soja e boi, destrói floresta, acaba água, acaba com os animais, passarinhos, peixe e deixa (os) 'índios' sem nada. Eu era daqui, eu vivia aqui, minha família era daqui. Mas se vou aí, no centro da cidade, olham para mim e dizem que sou estrangeiro, que sou boliviano. Eu digo que morava aqui antes de vocês (MOIA KAIABI, 2012). 
Educação na comunidade é primeiro ensinar (o) respeito ao outro e saber as coisas para viver (CACIQUE DA ETNIA WAURÁ, 2010).

Profundas reflexões foram desenvolvidas nesse contexto de diálogos, quer sobre o significado da educação, da escola, dos valores sociais, do cuidado com o outro, do cuidado com o meio. $\mathrm{O}$ relato aqui empreendido não consegue abarcar na totalidade a riqueza dos momentos desses encontros, considerados como altamente pedagógicos e construtivos a um olhar de entendimento e compreensão para com a cultura do outro.

A partir dos seminários, novos saberes e concepções foram construídos, culturas indígenas passaram a ter outro valor e significado aos professores em formação. A experiência foi profundamente enriquecedora e construiu caminhos a uma solidariedade orgânica intercultural.

Mais do que memorizar um conjunto vasto e extenso de nomes dos povos indígenas brasileiros, que existem na atualidade, ou colocar uma pena de ave na cabeça no "dia do índio", que pode se tornar algo vazio, descontextualizado e sem significado, os estudantes relataram que aprenderam o valor que cada cultura possui, que cada língua e modo de vida têm aos seus próprios componentes. Ainda, para viver precisam de um território para construir e manter sua existência. Nesse sentido, o debate para reconhecer e valorizar as culturas indígenas brasileiras passa também pela observação de um conjunto de questões como analisar e melhorar as condições desses povos originários e a educação que participam, uma vez que sociedades não indígenas que os circundam interferem no cotidiano indígena e por vezes destituem suas culturas e modos de vida.

Relatam os estudantes ainda que a riqueza dos diálogos constituiu uma possibilidade de humanização da educação universitária, conectada ao mundo da realidade social brasileira em sua diversidade linguística e cultural e que, posteriormente, poderá ser multiplicada na socialização escolar por ocasião da atuação profissional docente.

É preciso aprender a ver os indígenas. Hoje sabemos que é possível ensinar de modo totalmente diferente do que aprendemos, mostrando o contexto atual. Seria ridículo continuar a ensinar as crianças sobre os indígenas na escola simplesmente colocando aquela peninha na cabeça dos pequenos no dia do índio, sem dar explicação alguma, como se eles fossem um povo só e que não existem mais. Não se deve ensinar como se fosse um folclore, um faz-de-conta. É preciso fazer uma educação dentro da realidade (ALUNA DE GRADUAÇÃO, 2014).

Reconhecer e valorizar as culturas indígenas brasileiras é uma necessidade para a preservação dos povos, da riqueza, multiplicidade e diversidade cultural que pode e deve ser trabalhada na educação escolar, razão pela qual 
O diálogo educador entre indígenas e pedagogos(as) em formação: uma ponte para compreender e valorizar a diversidade cultural indígena brasileira

faz sentido que a formação de professores contemple e trabalhe em profundidade esta temática.

Nesse sentido, educar para o respeito e convivência é essencial na sociedade contemporânea, permitindo sempre a "co-presença" (SANTOS, 2007). O(A) educador(a) tem papel primordial na construção de processos de superação da reprodução de uma realidade de negação e discriminação que, por acontecer na sociedade, também acontece na escola. Os(As) educadores(as) terão de estar preparados ao exercício humanista na educação escolar, em primeiro lugar, porque os indígenas merecem respeito como humanos que são, mais do que simplesmente suas culturas constituírem patrimônio cultural. É certo que as culturas são sistemas de conhecimento do mundo e modos de agir no mundo que desaparecerão se desaparecer quem as opera e o espaço nas quais são construídas e desenvolvidas: a isto deve estar atenta a educação.

\section{CONSIDERAÇÕES}

A presença, o "face a face" e diálogo, ainda que breves, demonstraram ter força para a construção de caminhos que levam a uma posição de maior abertura, em coerência com a existência dos povos indígenas, sua diversidade cultural, sua participação na formação do povo brasileiro, da atualidade de sua existência, pela convivência, conhecimento e cooperação que possuem com a natureza e forma que educam suas crianças.

A presença dos indígenas na sala de aula de um curso de formação de educadores trouxe um contato pessoal, fazendo a visibilidade do "índio" constituinte de famílias, de comunidades, de aldeias e de povos ser a representação vivificada da nação brasileira. Os indígenas são pertencentes a um povo, a uma comunidade, sociedade e portadores de uma cultura. Em cada uma das etnias há um modo de ser.

O contato presencial na universidade, no curso de Pedagogia, como afirmado anteriormente, é a demonstração de uma realidade que traz uma situação afetiva, estabelece laços, apertos de mão, abraços, olhares, escutas de línguas e percepções diferentes e o mais essencial que é sentir o outro. Este sentir o outro é fundamental para seu reconhecimento e valorização.

Nesse sentido, justamente por intermédio da criatividade e do querer conhecer e entender o outro, que o diálogo educador entre indígenas e pedagogos(as), permite construírem-se as verdadeiras pontes para o compreender, valorizar e preservar da diversidade cultural indígena brasileira da era contemporânea. 
A universidade, enquanto formadora de professores, no contexto de alta diversidade étnica e cultural no Estado de Mato Grosso, precisa considerar essa situação como parte essencial de sua missão. Precisa intensificar seu compromisso social desenvolvendo a formação de professores não indígenas que ensinem o conhecimento e respeito à diversidade cultural indígena do país, do Estado e do entorno, assim como de outro modo o fez com o desenvolvimento da formação de professores indígenas.

\section{Agradecimentos}

Nosso agradecimento aos membros das comunidades indígenas, em especial xinguanas, que se fizeram presentes junto à Universidade do Estado de Mato Grosso, Campus de Sinop, nas atividades de formação de professores do curso de Pedagogia. Sua contribuição foi importante pela disposição, pelas palavras, pelo ensinamento de seus modos de vida e culturas, bem como em essencial, porque sua presença impulsiona à construção de uma nova educação que deve ter por base a superação do modelo integracionista e respeite os povos indígenas e suas culturas na diversidade que se apresentam. A participação de membros das comunidades indígenas nesta ação tem relação com o protagonismo que assumem quanto aos seus direitos e à preservação de suas culturas e territórios, no contexto problemático e discriminador da sociedade brasileira que replica a homogeneização há mais de cinco séculos, desrespeita os espaços e modos de vida indígena, processo intensificado com a globalização capitalista.

\section{REFERÊNCIAS}

BAMPI, Aumeri Carlos; DIEL, Jeferson Odair. Quando o índio educa o(a) pedagogo(a): relatos de pesquisa-ação nos Seminários de Antropologia junto ao curso de Pedagogia. Revista Cadernos de Educação Escolar Indígena, Cuiabá, MT, v. 12, n. 1, 2015.

FREIRE, José Ribamar Bessa. A imagem do índio e o mito da escola. Educação Escolar Indígena. In: MARFAN, Marilda Almeida (Org.). Congresso Brasileiro de Qualidade na Educação - formação de professores: educação indígena. Brasília: MEC, SEF, 2002. Disponível em: <http://www.dominiopublico.gov.br/download/texto/me000497. pdf>. Acesso em: 10 fev. 2014.

LUCIANO, Gersem dos Santos. O indio brasileiro: o que você precisa saber sobre os povos indígenas no Brasil de hoje. Brasília: Ministério da Educação, SECAD, LACED/ Museu Nacional, 2006. Disponível em: <http:/ / unesdoc. unesco.org/images/0015/001545/154565por.pdf>. Acesso em: 13 fev. 2013.

MARÍN, José. Globalização, educação e diversidade cultural. Revista Tellus, Campo Grande, MS, ano 6, n. 11, p. 35-60, out. 2006. 
O diálogo educador entre indígenas e pedagogos(as) em formação: uma ponte para compreender e valorizar a diversidade cultural indígena brasileira

OLIVEIRA, Roberto Cardoso de. O trabalho do antropólogo. São Paulo: Editora UNESP, 2000.

RIBEIRO, Darcy. O povo brasileiro: a formação e o sentido do Brasil. São Paulo: Companhia das Letras, 1995.

RODRIGUES, Aryon Dall'Igna. As línguas indígenas do Brasil. In: RICARDO, Beto; RICARDO, Fany (Ed.). Povos indígenas no Brasil 2001/2005. São Paulo: Instituto Socioambiental, 2006. p. 59-63.

SANTOS, Boaventura S. Para além do pensamento abissal: das linhas globais a uma ecologia de saberes. Novos Estudos Cebrap, São Paulo, n. 79, p. 71-94, nov. 2007.

SEKI, Lucy. Línguas indígenas do Brasil no limiar do século XXI. Impulso (edição sobre os 500 anos do Brasil), Piracicaba, SP, v. 12, n. 27, p. 233-256, 2000.

SILVA, Carlos Alberto Franco da. Fronteira agrícola capitalista e ordenamento territorial. In: SANTOS, Milton et al. Território, territórios: ensaios sobre o ordenamento territorial. 3. ed. Rio de Janeiro: Lamparina, 2007.

Recebido em 23 de setembro de 2016

Aprovado para publicação em 28 de novembro 2016 
